\title{
Coral recruitment and recovery after the 2004 Tsunami around the Phi Phi Islands (Krabi Province) and Phuket, Andaman Sea, Thailand
}

\author{
Y. Sawall $\cdot$ N. Phongsuwan $\cdot$ C. Richter
}

Received: 5 August 2009/Revised: 15 January 2010/ Accepted: 18 January 2010/Published online: 10 February 2010

(C) Springer-Verlag and AWI 2010

\begin{abstract}
The 2004 tsunami left a discontinuous pattern of destruction in the reefs along Andaman Sea coast of Thailand. Here, a comparative assessment of coral recruitment was carried out to assess differences in recovery between damaged and undamaged sites in nearshore fringing reefs 1 and 3 years after the tsunami. Settlement plates showed high frequencies of coral spat after 4 months $\left(<17\right.$ spat tile $\left.{ }^{-1}\right)$ in both, damaged and undamaged locations. Field surveys carried out 3 years after the tsunami on natural substrate confirmed that tsunami damage did not suppress recruitment in damaged sites relative to no impacted controls. New and stable settlement space along with unabated larval supply supported post-tsunami recruit densities up to $7.2 \mathrm{~m}^{-2}$ year $^{-1}$. Mean recruit densities were found at the level of post-storm situations with rapid recovery success, suggesting that the duration of disturbance, degree of sorting and, hence, stability of coral rubble is a key determinant of recruitment success. Low regeneration success of some species e.g. branching
\end{abstract}

Communicated by H.-D. Franke.

Electronic supplementary material The online version of this article (doi:10.1007/s10152-010-0192-5) contains supplementary material, which is available to authorized users.

Y. Sawall $(\bowtie)$

Leibniz Center for Tropical Marine Ecology (ZMT),

Fahrenheitstr. 6, 28359 Bremen, Germany

e-mail: yvonne.sawall@zmt-bremen.de

\section{N. Phongsuwan}

Phuket Marine Biological Center (PMBC),

P.O. Box 60, Phuket 83000, Thailand

C. Richter

Alfred-Wegener-Institute for Polar and Marine Research (AWI),

P.O. Box 120161, 27515 Bremerhaven, Germany acroporids and rebounding tourism industry at sites like Patong and partly around the Phi Phi Islands (dense carpets of filamentous algae) led to the assumption of selectivity and eventually to an alternation of the coral community even though live coral cover might be recovered soon.

Keywords Recovery - Recruitment · Corals · Tsunami · Destruction · Tourism

\section{Introduction}

The 26 December 2004 hitting the west coast of Thailand had a much higher impact on land than in the sea (DMCR 2005). During a rapid assessment 3 weeks after the event, only about $13 \%$ of the coral reefs in the Andaman Sea were found to be highly damaged ( $>50 \%$ of corals destroyed), while almost $40 \%$ showed no measurable impact by the tsunami (DMCR 2005). The degree of damage on coral reefs was found to be related to exposure to and amplification of the incident wave due to local differences in bathymetry and coastline leading to a localized pattern of destruction (Allen and Stone 2005; DMCR 2005). Generally, the highest impact was found between adjacent islands (funnelling effect) and in areas with shallow embayments or shallow exposed reefs (Phongsuwan et al. 2006). Corals were overturned (the massive Porites lutea and table corals such as some Acropora and Montipora spp.), broken (branching species e. g., Acropora spp.) or buried by debris or sediment, while less consolidated colonies slid away with the substrate (DMCR 2005).

So far, there is no precedent in the scientific literature for a coral recovery study after tsunami. Time spans for recovery after other large-scale mechanical disturbances such as tropical storms are highly variable, e.g. from only 
few years in storm-beaten reefs in Florida (Shinn 1976) and Phuket Island (Phongsuwan 1991), from few year to several decades in Heron Island, Australia (Woodhead quoted by Pearson 1981, Connell et al. 1997) and Hawaii (Dollar and Tribble 1993), and up to a century in British Honduras (Stoddart 1974). Other reefs may fail to recover altogether under continued unfavorable combinations of natural and anthropogenic stressors (Woodley et al. 1981; Woodley 1989; Rogers and Miller 2006).

Reef recovery is driven by two processes: sexual propagation with re-colonization of freshly exposed substrate by new recruits and asexually by regeneration of damaged coral colonies or fragments. The success of recolonization is dependent on larval supply, suitability of substrate as well and competition and predation (Pearson 1981). It is not known at present to what extent the tsunami may have affected any of these factors governing coral recruitment.

On the one hand, the small-scale patchiness of destruction both between and within reefs (DMCR 2005) may allow for an uninterrupted supply of larvae from undamaged to adjacent damaged reefs. On the other hand, the loss of more than half of the colonies in heavily impacted reefs may have rendered reproductive success critically low (Allee effect; Stephens and Sutherland 1999), particularly for short range dispersing species. Although connectivity between reefs has been emphasized for many reef organisms at various scales (e.g. Williams et al. 1984; Roberts 1997), self-seeding with a significant fraction of propagules settling within the natal reef has been shown, as well, in studies of larval dispersal (Sammarco and Andrews 1989; Black et al. 1990; Jones et al. 1999).

The success of re-colonization is also governed by the substrate composition. Well-sorted rubble following tropical cyclones in response to a high number $(>1,000)$ of huge waves, may provide a "killing field" for coral recruits (Thongtham and Chansang 1999, Tamelander 2002; Fox and Caldwell 2006). By contrast, unsorted rubble of various sizes, broken and overturned corals generated by large but few $(<10)$ tsunami waves may provide an interlocking framework, thus enhancing substrate stability and, hence, coral recruitment. These different substrate characteristics need to be considered in the recruitment process, together with the abundance of potential space competitors such as algae, expanding adult coral colonies and bryozoans. In terms of predation, corallivore fishes were rare and herbivore fishes were abundant in 'normal densities' before, as well as after the tsunami (Allen and Stone 2005).

Generally, the asexual process of regeneration proceeds smoothly, if the lesion is not too large and the coral is healthy (Knowlton et al. 1981; Woodley et al. 1981). For some branching species (e.g. Acropora spp.), mechanical fragmentation and subsequent regeneration is the dominant way of reproduction (Highsmith 1982), but also massive corals, such as Porites lutea dominating in the Andaman Sea of Thailand, are known for their rapid regeneration after damage (Highsmith 1980; Phongsuwan 1991; Brown et al. 2002).

The degree of damage determines the favorable mode of recovery, while heavy damage with high coral mortality results in a rather slow recovery process of re-colonization (Connell et al. 1997).

The aim of this study was to assess the recovery of tsunami impacted reefs relative to reefs less affected by destruction. Recruitment success was hypothesized to be high in areas with large areas of freshly exposed solid substrate in spite of a potentially patchy larval supply. Also, regeneration was expected to be rapid compared to results of previous studies (Phongsuwan 1991; Brown et al. 2002). The following variables influencing coral recruitment and potential reef recovery were investigated: (1) recruitment in damaged and undamaged sites, (2) abundance of suitable substrate for planula larvae to settle on, (3) abundance of potential space competitors of coral recruits and (4) survival of damaged corals. Two depths were chosen due to a much higher tsunami impact in the shallow reef ( $<4 \mathrm{~m}$ deep) compared to deeper areas.

The results of this study are discussed in the light of previous storm recovery studies in order to provide a baseline for conservation and management of the tsunami affected areas.

\section{Materials and methods}

\section{Study sites}

The study was carried out in reefs fringing the island of Phuket as well as the Phi Phi Islands in Phang Nga Bay, which were affected to various degrees by the 2004 tsunami. Two depths were chosen in the context of higher tsunami impact in the shallow reef area $(<4 \mathrm{~m})$. The Thai region features a monsoonal climate, where the wet and stormy SW monsoon season is from May to November, and the dry season with the calm NE monsoon is from December to April. In 2005, the SW monsoon was exceptionally dry in the beginning (except May) and above-average rainfall occurred during the end of the season (September-November) (Southern Meteorological Center, Thailand). The Andaman Sea is comparatively nutrient rich, due to upwelling and land run-off (Janekarn and Hylleberg 1989; Brown et al. 1999). In spite of growing anthropogenic pressures, the coral reefs are still in a fairly good condition (Brown 2007). 


\section{Phi Phi islands (Krabi Province)}

The Phi Phi Islands consist of 6 limestone islands located $40 \mathrm{~km}$ southeast of Phuket and about $30 \mathrm{~km}$ west of Krabi in Phang Nga Bay, a large shallow bay not deeper than $30 \mathrm{~m}$ (Fig. 1). Well-developed fringing coral reefs are found on the eastern sides of the islands or in areas protected from SW storms. At most sites, coral grow down to about 8-10 m depth, but to about 15-20 $\mathrm{m}$ at Ko Phi Phi Lae. The visibility ranges from 5 to $25 \mathrm{~m}$. Massive $P$. lutea, branching Acropora spp., such as $A$. formosa, A. grandis, A. subulata and A. austera and the tabular A. hyacinthus and A. subulata are the dominant species.

Although the Phi Phi Islands were declared a marine national park in 1983, unrestricted access by the tourism industry has led to the degradation of the surrounding reefs (Chou et al. 2002). There is no sewage treatment plant, only some collecting ponds and it remains unclear, where the wastewater enters the sea. Some of the coral reefs were strongly hit by the tsunami in December 2004 and suffered severe damage, while other areas remained untouched, providing an ideal setting for testing small-scale differences $(<10 \mathrm{~km})$ in coral recruitment as a function of reef damage.

Seven study sites were chosen, three damaged (marked with a ' $D$ ' superscript in the following) and four undamaged sites (Fig. 1). Highest tsunami damage occurred at Ko Pai and at Lolana Bay (up to 50\% damage) and at the northern end of Ko Phi Phi Lae (30-50\% damage) (DMCR 2005).

The remaining study sites Ko Yoong, Leam Tong, Hin Phae and Ko Phi Phi Lae SE were only slightly damaged or completely untouched (DMCR 2005).
Phuket

Coral reefs are well developed on the west coast in protected bays and on some areas along the southern coast. The study site South Patong in the Southwest of Phuket (Fig. 1) is a tourist hotspot with over 30,000 hotel bedrooms. Corals grow to about $7 \mathrm{~m}$ depth and the dominant species are P. lutea, D. heliopora, Millepora sp., H. coerulea, Lobophyllia sp., few branching corals such as $A$. formosa, few table corals and encrusting corals. About $30 \%$ of waste waters of the city of Patong are untreated and being discharged into the bay only a few hundred meters away from the investigated reef smothering the corals. The visibility is $5-10 \mathrm{~m}$.

South Patong is the only reef area on Phuket, which was severely impacted by the tsunami (DMCR 2005).

\section{Settlement plates}

A settlement experiment was carried out 1 year after the tsunami to evaluate coral larvae distribution between damaged and undamaged sites and to quantify spacecompeting algae and fouling organisms. From acrylic board $(2.5 \mathrm{~mm}$ thick), $12 \mathrm{~cm} \times 12 \mathrm{~cm}$ plates were cut, roughened with a metal brush and fixed in triplicates in a vertical position on 1-m iron rods. Six rods were fixed in an upright position for every location and depth (shallow: reef edge $\sim 3 \mathrm{~m}$ and deep: lower reef slope $\sim 7-10 \mathrm{~m}$ ) resulting in 2 depths $\times 6$ rods $\times 3$ plates $=36$ plates per study site. Although acrylic shares the disadvantages of all artificial settlement plate material compared so far in being highly selective for certain taxa (Harriott and Fisk 1987; Dunstan and Johnson 1998; Heyward and Negri 1999; Petersen et al. 2005; Mangubhai et al. 2007), as opposed to

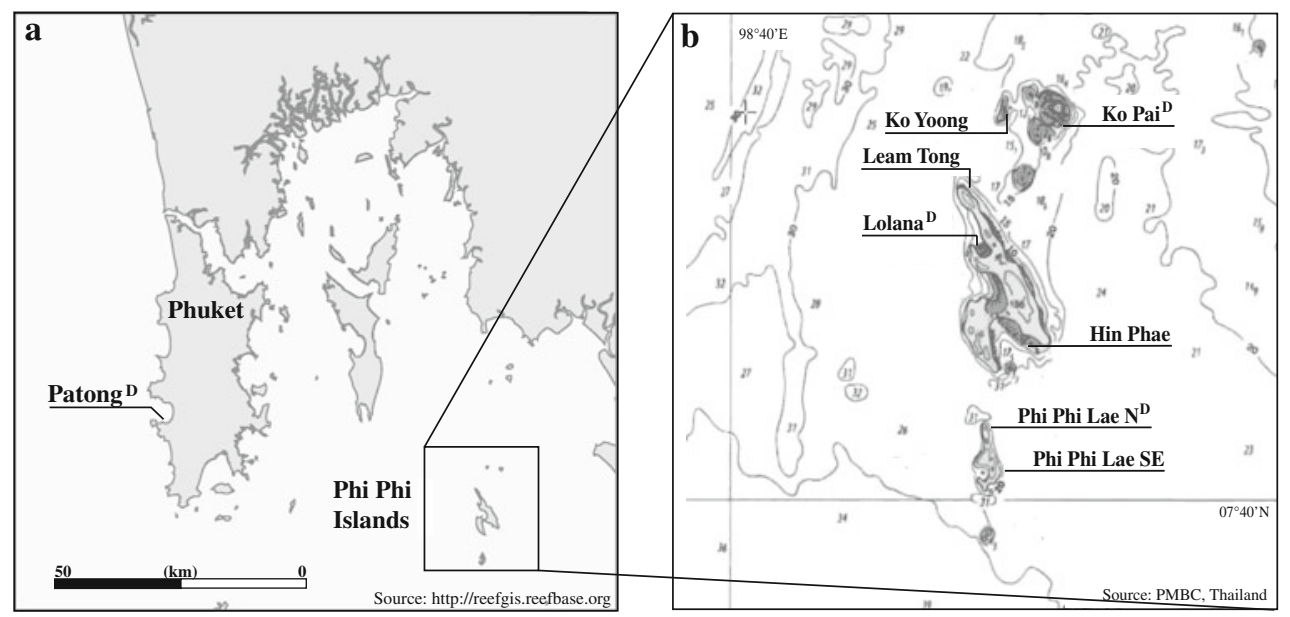

Fig. 1 Map of middle section of the Andaman coast of Thailand $\left(7.57^{\circ} \mathrm{N}-8.60^{\circ} \mathrm{N}\right)(\mathbf{a})$ and the Phi Phi Islands (b), indicating the study sites 
Table 1 Experiment design for one study site and depth including the intervals of plate replacements

\begin{tabular}{|c|c|c|c|c|}
\hline \multirow{2}{*}{} & \multicolumn{3}{|c|}{ exposure time } \\
\cline { 2 - 5 } & Nov - Dec & Dec - Jan & Jan - Feb & Feb - Mar \\
\hline rod 1 & 1 month & \multicolumn{3}{|c|}{3 months } \\
\hline rod 2 & \multicolumn{2}{|c|}{ 2 months } & \multicolumn{2}{|c|}{ 2 months } \\
\hline rod 3 & \multicolumn{3}{|c|}{4 months } & 1 month \\
\hline rod 4 & \multicolumn{3}{|c|}{4 months } \\
\hline rod 5 & \multicolumn{3}{|c|}{ 4 months } \\
\hline rod 6 & \multicolumn{3}{|c}{} \\
\hline
\end{tabular}

Exchanged plates (gray)

natural reef substrate (e.g.Morse and Morse 1996), they are nevertheless useful in detecting differences in coral recruitment in both, space and time.

All the settlement plates were deployed early November 2005. For a given site and depth, the triplicate plates of rod number one were replaced after 1 month, the plates of rod number two after 2 months, etc., resulting in a time series of settlement of varying exposure period (up to 4 months, early November 2005 to early March 2006; Table 1).

After removal, plates were allowed to dry in the sun for 2-3 days for examination with a magnifying glass and stereo microscope. Settlement plates were searched for coral spat and specimens identified to family level according to Babcock et al. (2003). The abundance of fouling organisms (filamentous algae, crustose coralline red algae and sessile fauna such as barnacles, bivalves, bryozoans and spirorbid worms) was recorded on an ordinal scale between 0 (absent) and 5 (replete). Category 5 applied to high densities of filamentous algae featuring long filaments; crustose coralline algae covering most of the plate in thick patches; bryozoans covering more than $40 \%$ of the plate; spirorbid worms in excess of 40 individuals per plate; bivalves and barnacles with more than 25 individuals per plate, respectively.

Statistical analyses were conducted with the software SAS. The data collected on one rod (3 plates) were treated as one replicate. A Poisson regression was carried out since the coral spat densities followed a Poisson distribution. The data set of the 4-month period was used to assess the effects of three indicator variables (1) 'status' (damaged, undamaged), (2) reef 'sites' (Ko Yoong, Leam Tong, Hin Phae, Phi Phi Lae SE, Phi Phi Lae N, Ko Pai, Lolana, Patong) and (3) 'depth' (shallow, deep) on the response variable 'coral spat' density, whereas 'sites' were nested within 'status'. The effects of filamentous and crustose coralline red algae and of fouling organisms (additional indicator variables) on coral spat densities were analyzed in a separate run of Poisson regression.

To test for differences in coral spat abundances between the two seasons (November-January end of rainy season, January-March dry season) data of the 2-month period were used and Poisson regression was applied. The additional indicator variable was 'season', however, the variable 'site' was eliminated, because each site was represented by only two data points (one deep rod, one shallow rod). The effect of seasonality on algae and fouling organisms was tested with univariate ANOVA using season and depth as fixed factors; and the sites were treated as replicates. Levene's test was applied to test homogeneity of residuals.

Succession over the 4-month period was analyzed graphically.

Visual census of coral recruits in situ

In this paper, we distinguish between newly settled corals ("coral spat") on settlement plates and the young corals ("coral recruits") in the field.

Visual census of coral recruits was done 1 year (January/February 2006) as well as 3 years (November 2007) after the tsunami in proximity to the settlement plates at all sites, along the reef edge and the lower reef slope in order to quantify the success of coral recruitment. Recruits were counted on natural substrate using a $0.5 \times 0.5 \mathrm{~m}$ square $\left(0.25 \mathrm{~m}^{-2}\right)$ placed at random $(n=10)$ in areas dominated by dead coral substrate and summed up (recruits $2.5 \mathrm{~m}^{-2}$ ). Within the quadrates, $0.5-2.0-\mathrm{cm}$ coral recruits (diameter) were recorded. Visual census with unaided eye allowed undoubted recruit identification only for the genus Pocillopora; all other scleractinians were recorded as "other". Given linear extension rates of $>1 \mathrm{~cm} \mathrm{year}^{-1}$ even for slow-growing taxa in the area (Phongsuwan 1991; Scoffin et al. 1992), it was assumed that the bulk of the recruits had settled after the tsunami.

For statistical analyses, Levene's test was applied to test homogeneity of residuals and univariate ANOVA was used to compare recruit abundances. Status and depth were fixed factors, and the sites were treated as replicates.

\section{Line intercept transects}

Line intercept transects (English et al. 1994) were carried out in January/February 2006 (i.e. 1 year after the tsunami) to determine live coral cover and the availability of suitable substrate for coral larvae settlement. With a measuring tape, $20-\mathrm{m}$ transects $(n=3)$ were laid out along the reef edge and the lower reef slope in proximity to the settlement plates at all sites. The substrate directly under the tape was assigned to the following categories-live coral (LC), dead coral (DC), other organisms (including soft coral, sponges and giant clams), coral rubble (RB), sand (SA), macroalgae and categories recorded to the nearest $\mathrm{cm}$. RB included small pieces of coral skeleton $(<10 \mathrm{~cm}$ long), while DC was composed of coral skeleton pieces larger than RB, 
dead patches on coral colonies and entire dead colonies up to few meters in diameter. The respective mean percentage cover of each component was calculated for each location and depth.

\section{Results}

Settlement plates

\section{Coral spat}

Pocilloporids dominated by far the coral spat on the settlement plates, in spite of the dominance of adult Acroporidae and Poritidae in the reefs. Spat were patchily distributed between the plates, ranging from 0 to 17 spat plate $^{-1}$ and a total of 394 spat for all plates. Coral spat densities were lower during the first 2 months of the experiment (November 2005-January 2006), compared to the last 2 months (January-March 2006) (Table 3; Fig. 2). There was no detectable difference between damaged and undamaged sites after 4 months. More coral spat were found in the deeper areas; however, the difference between the 2 depths varied between damaged and undamaged sites (Table 3) and the high number of coral spat at Ko Yoong deep (Table 2) strongly influenced this result. The high variations in spat abundances between the sites led to site effects at all sites in damaged as well as in undamaged reefs (Table 3, Online Resource 1 shows graphical illustration of spat densities).

Coral recruitment showed a functional response to filamentous algae with highest coral spat densities on plates with intermediate algae cover (Online Resource 2).
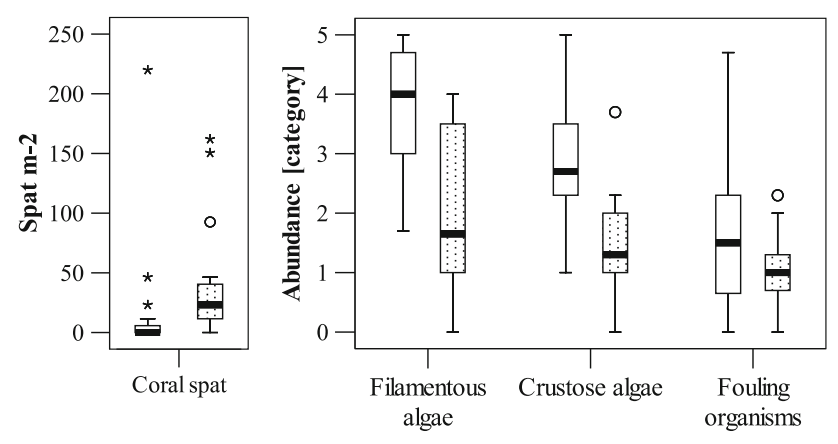

Fig. 2 Abundance of coral spat, filamentous algae, crustose algae and fouling organisms after 2 months: November 2005-January 2006 (blank), January-March 2006 (dotted), indicates seasonality. The $y$ axis represents the categories of abundance/density: $1=$ very low, $5=$ very dense/high abundance. Box: lower/upper quartile and median (bold black line); whisker (vertical line): extend of rest of the data; outliers: circle: measured value is higher/smaller than the upper/lower quartile $+1.5 \times$ quartile distance, star: measured value is higher/smaller than the upper/lower quartile $+3 \times$ quartile distance
A positive relationship between crustose coralline red algae and coral spat (Morse and Morse 1996) was not detectable.

\section{Algae and fouling organisms}

Filamentous and crustose coralline red algae showed a clear seasonality with a higher abundance within the first 2 months (Fig. 2, ANOVA $P<0.001$ for both). Depth had no effect on the distribution of filamentous algae (ANOVA $P>0.05)$. However, crustose red algae were significantly more abundant in the shallow reefs (ANOVA $P=0.016$ ). There were pronounced differences in algal cover between sites: Lolana ${ }^{\mathrm{D}}$ had the highest abundance of filamentous algae followed by Patong ${ }^{\mathrm{D}}$, while the lowest densities were found at Leam Tong and Phi Phi Lae SE (Online Resource 3). Sediment was trapped between the algal filaments of densely covered plates especially in the deeper area of Ko Yoong and Lolana ${ }^{\mathrm{D}}$.

Highest abundances of crustose algae were found at Ko $\mathrm{Pai}^{\mathrm{D}}$ and Lolana ${ }^{\mathrm{D}}$ displaying thick algae crusts on the plates.

Although the abundance of fouling organisms (bryozoans, spirorbid worms, bivalves, barnacles) was generally low, some plates had high abundances of certain groups (e.g. spirorbid worms) and variation was sometimes high on the level of a single rod. Peak abundances were visible in the deeper area of Patong ${ }^{\mathrm{D}}$, where bryozoans $(>40 \%$ coverage) and bivalves (9-15 ind. plate ${ }^{-1}$ ) showed the highest abundances. Seasonality was not significant, but showed a similar pattern as filamentous and crustose algae (Fig. 2, ANOVA $P>0.05$ ). An overgrowth of spat by bryozoans was observed in some cases.

Succession took place following the expected pattern, in which filamentous algae and crustose coralline red algae are the first settlers being than gradually replaced by sessile animals, such as bryozoans and bivalves and finally by corals (Online Resource 4).

\section{Coral recruits on natural substrate}

There was a significant increase in coral recruitment between one and 3 years after the tsunami (ANOVA $P=0.016$ ), but no differences between either damaged and undamaged or shallow and deep reefs (ANOVA $P>0.05)$. One year after the tsunami, the highest density of recruits was found at Lolana $\mathrm{Bay}^{\mathrm{D}}$ with more than 6 recruits $\mathrm{m}^{-2}$ in the shallow reef area followed by Leam Tong. Almost 2 years later, Ko Yoong showed the highest recruit density and Lolana $\mathrm{Bay}^{\mathrm{D}}$ was situated around the average of all sites (Table 4). Generally, pocilloporids contributed the bulk of the recruits; but variation between sites was very large ranging from $0 \%$ pocilloporids in shallow Hin Phae after 1 year to $100 \%$ in shallow Leam Tong after 3 years (Table 4). 
Table 2 Coral spat abundances on settlement tiles with an exposure time of 4 months

\begin{tabular}{|c|c|c|c|c|c|c|c|c|c|c|}
\hline & \multicolumn{2}{|l|}{ Spat tile ${ }^{-1}$} & \multicolumn{2}{|c|}{ Pocilloporidae (\%) } & \multicolumn{2}{|c|}{ Acroporidae (\%) } & \multicolumn{2}{|c|}{ Poritidae (\%) } & \multicolumn{2}{|c|}{ Others $(\%)$} \\
\hline & Shallow & Deep & Shallow & Deep & Shallow & Deep & Shallow & Deep & Shallow & Deep \\
\hline Ko Yoong & 0 & $8.9 \pm 4.7$ & 0 & 97 & 0 & 0 & 0 & 3 & 0 & 0 \\
\hline Leam Tong & $2.8 \pm 2.4$ & $0.3 \pm 1.0$ & 96 & 100 & 0 & 0 & 0 & 0 & 4 & 0 \\
\hline Hin Phae & $0.6 \pm 0.9$ & $2.6 \pm 1.9$ & 100 & 88 & 0 & 0 & 0 & 9 & 0 & 3 \\
\hline PP Lae SE & $1.6 \pm 2.3$ & 0 & 100 & 0 & 0 & 0 & 0 & 0 & 0 & 0 \\
\hline PP Lae $\mathrm{N}^{\mathrm{D}}$ & $0.7 \pm 1.4$ & 0 & 77 & 0 & 8 & 0 & 0 & 0 & 15 & 0 \\
\hline Ko $\mathrm{Pai}^{\mathrm{D}}$ & $1.2 \pm 1.9$ & $0.6 \pm 0.7$ & 94 & 100 & 0 & 0 & 0 & 0 & 6 & 0 \\
\hline Lolana $^{\mathrm{D}}$ & $0.7 \pm 1.1$ & $0.3 \pm 0.5$ & 81 & 67 & 0 & 17 & 13 & 17 & 6 & 0 \\
\hline Patong ${ }^{\mathrm{D}}$ & $3.3 \pm 2.4$ & $0.6 \pm 1.1$ & 95 & 33 & 0 & 33 & 4 & 17 & 2 & 17 \\
\hline
\end{tabular}

Average \pm standard deviation

Table 3 Results of Poisson regression: coral spat dependency on status (damaged/undamaged), depth and site (nested within status), using the 4-month data; effect of season, using 2-month data; effect of algae and fouling organisms on coral spat abundances, using 4-month data

\begin{tabular}{lcccl}
\hline Source & $d f$ & SE & $\chi^{2}$ & $P$ \\
\hline Coral spat (status and depth) & & & & \\
Status & 1 & 0.2443 & 0.20 & $\mathrm{~ns}$ \\
Depth & 1 & 0.1782 & 19.00 & $<0.0001$ \\
Status $\times$ depths & 1 & 0.3571 & 37.33 & $<0.0001$ \\
Site (status) Ko Yoong & 0 & 0.0000 & - & - \\
Site (status) Leam Tong & 1 & 0.2196 & 22.86 & $<0.0001$ \\
Site (status) Hin Phae & 1 & 0.2327 & 26.76 & $<0.0001$ \\
Site (status) PPLae SE & 1 & 0.2897 & 36.20 & $<0.0001$ \\
Site (status) PPLae N & 1 & 0.4419 & 15.93 & $<0.0001$ \\
Site (status) Ko Pai ${ }^{\mathrm{D}}$ & 1 & 0.3018 & 6.73 & 0.0095 \\
Site (status) Lolana ${ }^{\mathrm{D}}$ & 1 & 0.3737 & 13.20 & 0.0003 \\
Site (status) Patong & 0 & 0.0000 & - & - \\
Coral spat (season) & & & & \\
Season & 1 & 0.2367 & 11.00 & 0.0009 \\
Coral spat (algae and fouling organisms) & & \\
Filamentous algae & 1 & 0.1395 & 55.27 & $<0.0001$ \\
Crustose algae $^{\mathrm{D}}$ & 1 & 0.1318 & 8.64 & 0.0038 \\
Fouling organisms $^{\mathrm{D}}$ & 1 & 0.1809 & 0.08 & $\mathrm{~ns}$ \\
\hline
\end{tabular}

$n s$ Not significant. $P<0.05$ significant

No relationship was visible between the number of spat and the number of recruits for either pocilloporid corals alone or the ensemble of corals. At Ko Yoong, which showed an extremely high abundance of pocilloporids on the plates, the number of recruits was found within the range of other sites (Tables 2, 4). Also, no connection between recruit densities and algae abundance (on plates) could be found (Online Resource 5).

Additionally to the $<1$-year-old recruits some older recruits (1-3 years), in particular fast growing Acropora spp. (10-20 cm in diameter), were observed during the
November 2007 survey on tsunami-generated dead corals at Lolana Bay ${ }^{\mathrm{D}}$ and Patong ${ }^{\mathrm{D}}$.

Substrate composition and survival of damaged corals

Highest LC cover was found at Ko Yoong in the shallow reef $(57 \%)$. In five out of eight cases, a higher LC cover was found in the shallow area; the opposite situation was observed at Lolana ${ }^{\mathrm{D}}$ and Patong ${ }^{\mathrm{D}}$ and Hin Phae. The cover by DC was highest in the shallow areas of damaged reefs in particular at $\mathrm{Ko} \mathrm{Pai}^{\mathrm{D}}$ and Lolana ${ }^{\mathrm{D}}$ with $59 \%$ largely due to overturned Porites heads. But also the deeper reef areas showed a higher abundance of DC compared to the undamaged sites. In contrast, we found no relation between RB cover and tsunami impact. The only site with high rubble cover was Phi Phi Lae SE deep with $49 \%$, while the other sites were lying generally between 10 and $20 \%$ at other sites (Fig. 3, Online Resource 6 presentation in numbers). No correlation was found between LC and coral recruit densities.

Many of the overturned or toppled Porites heads survived, showing partial re-growth around the edges. Branching coral species such as Acropora spp. were severely impacted in some areas; many fragments were dead in the shallow water, particularly on the reef flat. Some fragments on the reef slope survived and showed new outgrowth, unless covered by sand or debris. Dead Acropora table corals were found uprooted in the sand and toppled over specimens in no direct contact with the sediment were found alive even in an upside down position. New little outgrowths directed to the light could be observed.

\section{Discussion}

The densities of coral spat recorded on the settlement tiles as well as the recruit abundances on the natural substrates 
Table 4 Coral recruit abundances on natural substrate

\begin{tabular}{|c|c|c|c|c|c|c|c|c|c|c|c|c|}
\hline & \multicolumn{6}{|c|}{ January/February 2006} & \multicolumn{6}{|c|}{ November 2007} \\
\hline & \multicolumn{2}{|c|}{ Recruits $\mathrm{m}^{-2}$} & \multicolumn{2}{|c|}{ Pocilloporidae $\mathrm{m}^{-2}$} & \multicolumn{2}{|c|}{ Others $\mathrm{m}^{-2}$} & \multicolumn{2}{|c|}{ Recruits $\mathrm{m}^{-2}$} & \multicolumn{2}{|c|}{ Pocilloporidae $\mathrm{m}^{-2}$} & \multicolumn{2}{|c|}{ Others $\mathrm{m}^{-2}$} \\
\hline & Shallow & Deep & Shallow & Deep & Shallow & Deep & Shallow & Deep & Shallow & Deep & Shallow & Deep \\
\hline Ko Yoong & 2.8 & 2.8 & 1.6 & 1.6 & 1.2 & 1.2 & 7.2 & 5.6 & 4.8 & 3.2 & 2.4 & 2.4 \\
\hline Leam Tong & 4.8 & 3.2 & 3.6 & 1.6 & 1.2 & 3.2 & 2.8 & 4.0 & 2.8 & 0.8 & 0.0 & 3.2 \\
\hline Hin Phae & 1.2 & 2.0 & 0.0 & 0.0 & 1.2 & 1.2 & 3.2 & 3.2 & 1.2 & 1.2 & 2.0 & 2.0 \\
\hline PPLae SE & 2.4 & 1.6 & 1.6 & 0.8 & 0.8 & 1.2 & 6.4 & 2.4 & 4.0 & 0.0 & 2.4 & 2.4 \\
\hline PPLae $\mathrm{N}^{\mathrm{D}}$ & 3.2 & 3.2 & 0.4 & 0.4 & 2.8 & 2.8 & 2.8 & 4.4 & 0.8 & 0.4 & 2.0 & 4.0 \\
\hline Ko Pai ${ }^{\mathrm{D}}$ & 2.4 & 1.2 & 0.8 & 0.4 & 1.6 & 0.8 & 3.2 & 4.4 & 1.6 & 1.6 & 1.6 & 2.8 \\
\hline Lolana $^{\mathrm{D}}$ & 6.4 & 3.2 & 2.4 & 0.8 & 4.0 & 2.4 & 4.8 & 4.8 & 2.4 & 0.4 & 2.4 & 4.4 \\
\hline Patong $^{\mathrm{D}}$ & 4.0 & 2.0 & 1.2 & 0.8 & 2.8 & 1.2 & 6.4 & 2.4 & 2.8 & 0.0 & 3.6 & 2.4 \\
\hline
\end{tabular}

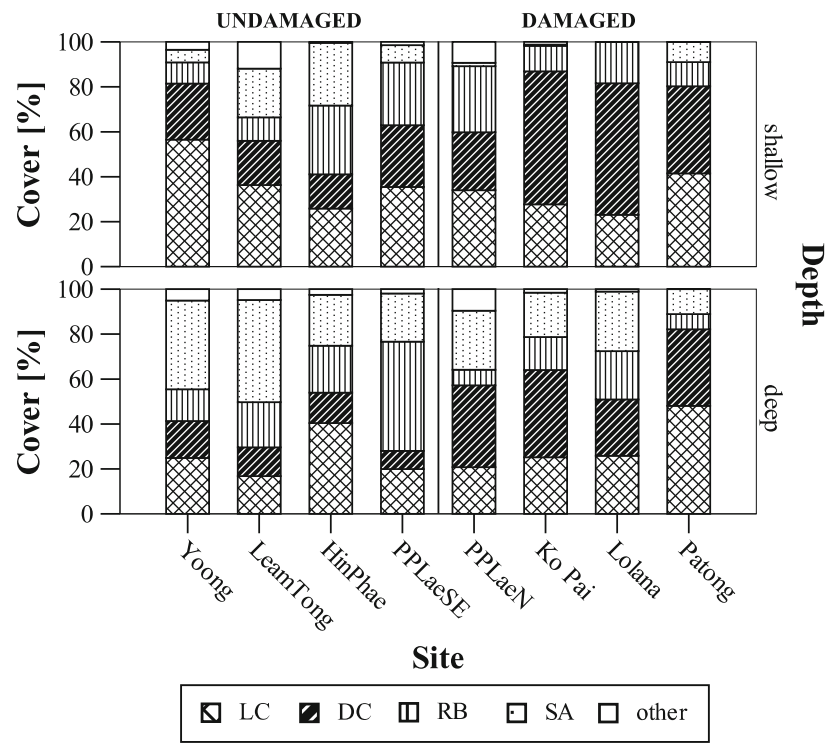

Fig. 3 Substrate composition at different sites and depths

indicate a successful supply of coral larvae and subsequent recruitment not only in the undamaged but also in the damaged reef areas. Although the predominance of pocilloporids on the settlement plates is likely biased, similar to the overrepresentations found in other settlement plate studies (Bak and Engel 1979; Harriott and Fisk 1987; Dunstan and Johnson 1998), the high densities show that these monthly reproducing brooders (Fadlallah 1983) are able to disperse to sites featuring only sparse adult brood stock over a range of several kilometers (cf. Table 5).

The high spat densities are reflected also in the densities of coral recruits on natural substrate, which increased from an average $3.2 \pm 1.6 \mathrm{~m}^{-2}$ in damaged areas and to $4.15 \pm 1.3 \mathrm{~m}^{-2}$ after 3 years. While these findings suggest successful recovery, it must be kept in mind that the natural variability in recruitment between years can be pronounced (Dunstan and Johnson 1998). These results are lying within
Table 5 Abundance of Pocilloporidae adults, spat and recruits

\begin{tabular}{llll}
\hline & $\begin{array}{l}\text { Adult } \\
{[\% \text { of LC] }}\end{array}$ & $\begin{array}{l}\text { Spat } \\
{\left[\text { no. } \mathrm{m}^{-2}\right]}\end{array}$ & $\begin{array}{l}\text { Recruits } \\
{\left[\text { no. }^{-2}\right]}\end{array}$ \\
\hline Ko Yoong & 10.96 & 137 & 1.5 \\
Leam Tong & 1.80 & 48 & 1.8 \\
Hin Phae & 0.51 & 42 & 0.4 \\
PPLaeSE & $\mathrm{ND}$ & 25 & 1.0 \\
PPLaeN $^{\mathrm{D}}$ & $\mathrm{ND}$ & 11 & 0.4 \\
Ko Pai $^{\mathrm{D}}$ & 0.00 & 23 & 0.6 \\
Lolana $^{\mathrm{D}}$ & 0.00 & 16 & 1.5 \\
Patong $^{\mathrm{D}}$ & 0.46 & 52 & 1.0 \\
\hline
\end{tabular}

Damaged sites $\left({ }^{\mathrm{D}}\right)$

$N D$ no data

the recruit densities found during a 30-year study in the Great Barrier Reef (1.8-30.3 recruits year ${ }^{-1}$ ). The high fluctuation in the GBR was partly attributed to storm events and partly to natural temporal variability, while the recovery success after different storms was found to be strongly influenced by the severity of storm impact (Connell et al. 1997). At a storm-beaten reef in the Andaman Sea of Thailand, high recruitment success was found (1719 recruits $\mathrm{m}^{-2}$, size $<5 \mathrm{~cm} \varnothing$ ) due to the abundance of solid substrate (Phongsuwan 1991). Nevertheless, our results are outstanding compared to another storm-shattered reef in the area, where low recruitment success was the consequence of long-lasting unconsolidated rubble (2-4 recruits $\mathrm{m}^{-2}$, size $<5 \mathrm{~cm} \varnothing$ ) (Thongtham and Chansang 1999). This leads to the suggestion that substrate stability plays a decisive role in recovery after large-scale disturbance. In the context of tsunami, few but very energetic waves creates a heterogeneous and interlocking framework with coral debris of various forms and sizes. This was typical for reefs strongly hit by the tsunami such as Lol${ }_{a n a}{ }^{\mathrm{D}}$ and $\mathrm{Ko} \mathrm{Pai}^{\mathrm{D}}$, where dead corals (59\%) provide a solid foundation with a high variation of substrate orientation and surface complexity, which is known to be supportive 
for larval settlement and survival (Pearson 1981; Thongtham and Chansang 1999).

Space-competing organisms such as algae and a range of small filter feeders did not seem to have a negative impact on coral spat and recruit densities leading to the conclusion of a rather high resilience of corals in the Andaman Sea being able to successfully compete with other organisms. This idea is further supported by other studies in this area, in which high recruitment success and regeneration of damaged coral colonies after storms, sediment plumes from dredging, negative sea level anomalies and increased sea surface temperatures were found (Phongsuwan 1991; Brown et al. 2002; Brown and Phongsuwan 2004). Additional evidence for the corals ability to persist and/or recover quickly are (1) high growth rates (Phongsuwan 1991; Scoffin et al. 1992), (2) high tolerance for sedimentation and elevated nutrient levels (Brown 2007) and (3) preferred spawning during the end of the dry season when algae growth is suppressed as shown in our results of the settlement plates and also found by Chanmethakul (2001) and Guest et al. (2005). Latter might also be a reason for the low contribution of many coral species on the settlement tiles, where plates were removed (March) just after the onset of the spawning period (February).

After demonstrating all the positive features of corals in this region, some weakness in the recovery of branching acroporids was found. In contrast to massive (e.g. Porites lutea, faviids) and table-like corals (e.g. Acropora hyacinthus, A. clathrata, Montipora spp.), regeneration by tissue re-sheeting was hardly visible in branching Acropora spp. resulting in high mortality rates. Only few coral fragments were still alive after 3 years-in spite of its alleged fast fixation (Phongsuwan 2006) and their naturally high recovery potential (Highsmith 1982; Veron 1993). This goes in line with the findings at a reef off Phuket, where recovery of branching acroporids after stress from low sea levels and increased temperature was unsuccessful in contrast to other species (Brown and Phongsuwan 2004).

After all, this might lead to selection of coral species not only concerning the regeneration process but consequently also the recruitment diversity. Unfortunately, the recruitment diversity has not been assessed; however, the relatively high contribution of pocilloporids and the intermediate numbers of coral recruits support the idea of selectivity. Even though the percentages of live coral cover might be restored, lower diversity in areas with strongly degrading water quality such as Patong and partly around the Phi Phi Islands (Chou et al. 2002; Yeemin 2004) might be the consequence.

Therefore, higher sensitivity of the coral community cannot be ruled out, which leads to a higher vulnerability of a reef ecosystem to natural disturbances e.g. heavy storms.
This emphasizes the need of further monitoring activities and the need of effective coastal management to maintain viable conditions for Andaman Sea coral reefs, especially where tourism is growing in great numbers.

Acknowledgments We thank the scientists of Phuket Marine Biological Center (PMBC), in particular Dr. Nalinee Thongtham, Dr. Suree Satapoomin and Dr. Somkiat Khokiattiwong for their advice and logistic support, the technicians at PMBC and Andrew Hewett (Phi Phi Dive Camp) for their field assistance and Gerrit Nanninga for his support throughout the period in Thailand. This work was funded by Deutsche Gesellschaft für Technische Zusammenarbeit (GTZ; PN: 95.3506.3) and ZMT.

\section{References}

Allen GR, Stone GS (2005) Rapid assessment survey of tsunamiaffected reefs of Thailand. New England Aquarium Technical Report 02-05, Boston, USA, $122 \mathrm{pp}$

Babcock RC, Baird AH, Piromvaragorn S, Thomson DP, Willis BL (2003) Identification of scleractinian coral recruits from IndoPacific reefs. Zool Stud 42:211-226

Bak RPM, Engel MS (1979) Distribution, abundance and survival of juvenile hermatypic corals (Scleractinia) and the importance of life-history strategies in the parent coral community. Mar Biol 54:341-352

Black KP, Gay SL, Andrews JC (1990) Residence times of neutrallybuoyant matter such as larvae, sewage or nutrients on coral reefs. Coral Reefs 9:105-114

Brown BE (2007) Coral reefs of the Andaman Sea-an integrated perspective. Oceanogr Mar Biol Annu Rev 45:173-194

Brown BE, Phongsuwan N (2004) Constancy and change on shallow reefs around Leam Panwa, Phuket, Thailand over a twenty year period. Phuket Mar Biol Cent Res Bull 65:61-73

Brown BE, Dunne RP, Ambarsari I, Le Tissier MDA, Satapoomin U (1999) Seasonal fluctuations in environmental factors and variations in symbiotic algae and chlorophyll pigments in four Indo-Pacific coral species. Mar Ecol Prog Ser 191:53-69

Brown BE, Clarke KR, Warwick RM (2002) Serial patterns of biodiversity change in corals across shallow reef flats in Ko Phuket, Thailand, due to the effects of local (sedimentation) and regional (climatic) perturbations. Mar Biol 141:21-29

Chanmethakul (2001) Spawning season of scleractinian corals on Phuket Island. M.Sc. thesis, Prince of Songkla University, Thailand, $82 \mathrm{pp}$

Chou LM, Tuan VS, Reefs P, Yeemin T, Cabanban A, Kessna S, Kessna I (2002) Status of Southeast Asia coral reefs. In: Wilkinson C (ed) Status of coral reefs of the world. Australian Institute of Marine Science, Townsville, pp 123-153

Connell JH, Hughes TP, Wallace CC (1997) A 30-year study of coral abundance, recruitment, and disturbance at several scales in space and time. Ecol Monog 67:461-488

DMCR-Department of Marine, Coastal Resources (2005) Rapid assessment of the tsunami impact on marine resources in the Andaman Sea, Thailand. Phuket Marine Biological Center, Thailand

Dollar SJ, Tribble GW (1993) Recurrent storm disturbance and recovery-a long-term study of coral communities in Hawaii. Coral Reefs 12:223-233

Dunstan PK, Johnson CR (1998) Spatio-temporal variation in cores recruitment at different scales on Heron Reef, southern Great Barrier Reef. Coral Reefs 17:71-81 
English S, Wilkinson C, Baker V (eds) (1994) Survey manual for tropical marine resources. Australian Institute of Marine Science, Townsville

Fadlallah YH (1983) Sexual reproduction, development and larval biology in scleractinian corals. Coral Reefs 2:129-150

Fox HE, Caldwell RL (2006) Recovery from blast fishing on coral reefs: a tale of two scales. Ecol Appl 16:1631-1635

Guest JR, Baird AH, Goh BPL, Chou LM (2005) Seasonal reproduction in equatorial reef corals. Invertebr Reprod Dev 48:207-218

Harriott VJ, Fisk DA (1987) A comparison of settlement plate types for experiments on the recruitment of scleractinian corals. Mar Ecol Prog Ser 37:201-208

Heyward AJ, Negri AP (1999) Natural inducers for coral larval metamorphosis. Coral Reefs 18:273-279

Highsmith RC (1980) Passive colonization and asexual colony multiplication in the massive coral Porites lutea Milne Edwards and Haime. J Exp Mar Biol Ecol 47:55-67

Highsmith RC (1982) Reproduction by fragmentation in corals. Mar Ecol Prog Ser 7:207-226

Janekarn V, Hylleberg J (1989) Coastal and offshore primary production along the west coast of Thailand (Andaman Sea) with notes on physical-chemical variables. Phuket Mar Biol Cent Res Bull 51:1-120

Jones GP, Milicich MJ, Emslie MJ, Lunow C (1999) Self-recruitment in a coral reef fish population. Nature 402:802-804

Knowlton N, Lang JC, Rooney MC, Clifford P (1981) Evidence for delayed mortality in hurricane-damaged Jamaican staghorn corals. Nature 294:251-252

Mangubhai S, Harrison PL, Obura DO (2007) Patterns of coral larval settlement on lagoon reefs in the Mombasa Marine National Park and Reserve, Kenya. Mar Ecol Prog Ser 348:140-150

Morse ANC, Morse DE (1996) Flypapers for coral and other planktonic larvae. Bioscience 46:254-262

Pearson RG (1981) Recovery and recolonization of coral reefs. Mar Ecol Prog Ser 4:105-122

Petersen D, Laterveer M, Schuhmacher H (2005) Innovative substrate tiles to spatially control larval settlement in coral culture. Mar Biol 146:937-942

Phongsuwan N (1991) Recolonization of a coral reef damaged by a storm on Phuket Island, Thailand. Phuket Mar Biol Cent Res Bull 56:75-83

Phongsuwan N (2006) The use of coral transplantation in the rehabilitation of coral reefs affected by the 2004 tsunami. In: Plathong S (ed) Coral reef rehabilitation after the tsunami 2004 - case studies from Thailand. Department of Marine and Coastal Resources, Bangkok, pp 60-72

Phongsuwan N, Yeemin T, Worachananant S, Duangsawasdi M, Chotiyaputta C, Comley J (2006) Post-tsunami status of coral reefs and other coastal ecosystems on the Andaman Sea Coast of Thailand. In: Wilkinson C, Souter D, Goldberg J (eds) Status of coral reefs in tsunami affected countries: 2005. Australian Institute of Marine Science, Townsville, pp 63-77

Roberts CM (1997) Connectivity and management of Caribbean coral reefs. Science 278:1454-1457

Rogers CS, Miller J (2006) Permanent 'phase shifts' or reversible declines in coral cover? Lack of recovery of two coral reefs in St. John, US Virgin Islands. Mar Ecol Prog Ser 306:103-114

Sammarco PW, Andrews JC (1989) The Helix experiment-differential localized dispersal and recruitment patterns in Great Barrier-Reef corals. Limnol Oceanogr 34:896-912

Scoffin TP, Tudhope AW, Brown BE, Chansang H, Cheeney RF (1992) Patterns and possible environmental controls of skeletogenesis of Porites lutea, South Thailand. Coral Reefs 11:1-11

Shinn EA (1976) Coral reef recovery in Florida and Persian Gulf. Environ Geol 1:241-254

Stephens PA, Sutherland WJ (1999) Consequences of the Allee effect for behavior, ecology and conservation. Trends Ecol Evol 14:401-405

Stoddart DR (1974) Post-hurricane changes on the British Honduras reefs: re-survey of 1972. Proceedings of the 2nd International Coral Reef Symposium 2:473-483

Tamelander J (2002) Coral recruitment following a mass mortality event. Ambio 31:551-557

Thongtham N, Chansang H (1999) Influence of surface complexity on coral recruitment at Maiton Island, Phuket, Thailand. Phuket Mar Biol Cent Res Bull 20:93-100

Veron JEN (1993) Corals of Australia and the Indo Pacific. University of Hawai'i Press, Honolulu

Williams DM, Wolanski E, Andrews JC (1984) Transport mechanisms and the potential movement of planktonic larvae in the Central Region of the Great Barrier-Reef. Coral Reefs 3:229236

Woodley JD (1989) The effects of hurricane Gilbert on coral reefs at Discovery Bay. In: UNEP: assessment of the economic impacts of Hurricane Gilbert on coastal and marine resources in Jamaica. CEP Technical Report No. 4. UNEP Caribbean Environment Programme, Kingston, Jamaica, Appendix 9

Woodley JD, Chornesky EA, Clifford PA, Jackson JBC, Kaufman LS, Knowlton N, Lang JC, Pearson MP, Porter JW, Rooney MC, Rylaarsdam KW, Tunnicliffe VJ, Wahle CM, Wulff JL, Curtis ASG, Dallmeyer MD, Jupp BP, Koehl MAR, Neigel J, Sides EM (1981) Hurricane Allens impact on Jamaican coral reefs. Science 214:749-755

Yeemin T (2004) Status of coral reefs in Southeast Asian countries: Thailand. In: Japan Wildlife Research Center (ed) Status of coral reefs in East Asian seas region: 2004. Ministry of Environment, Tokyo, pp 71-94 